Document downloaded from:

http://hdl.handle.net/10251/167801

This paper must be cited as:

Villena, F.; García-Segura, T.; Pellicer, E. (2020). Drivers of Innovation Using BIM in Architecture, Engineering, and Construction Firms. American Society of Civil Engineers. 210-222. https://doi.org/10.1061/9780784482889.023

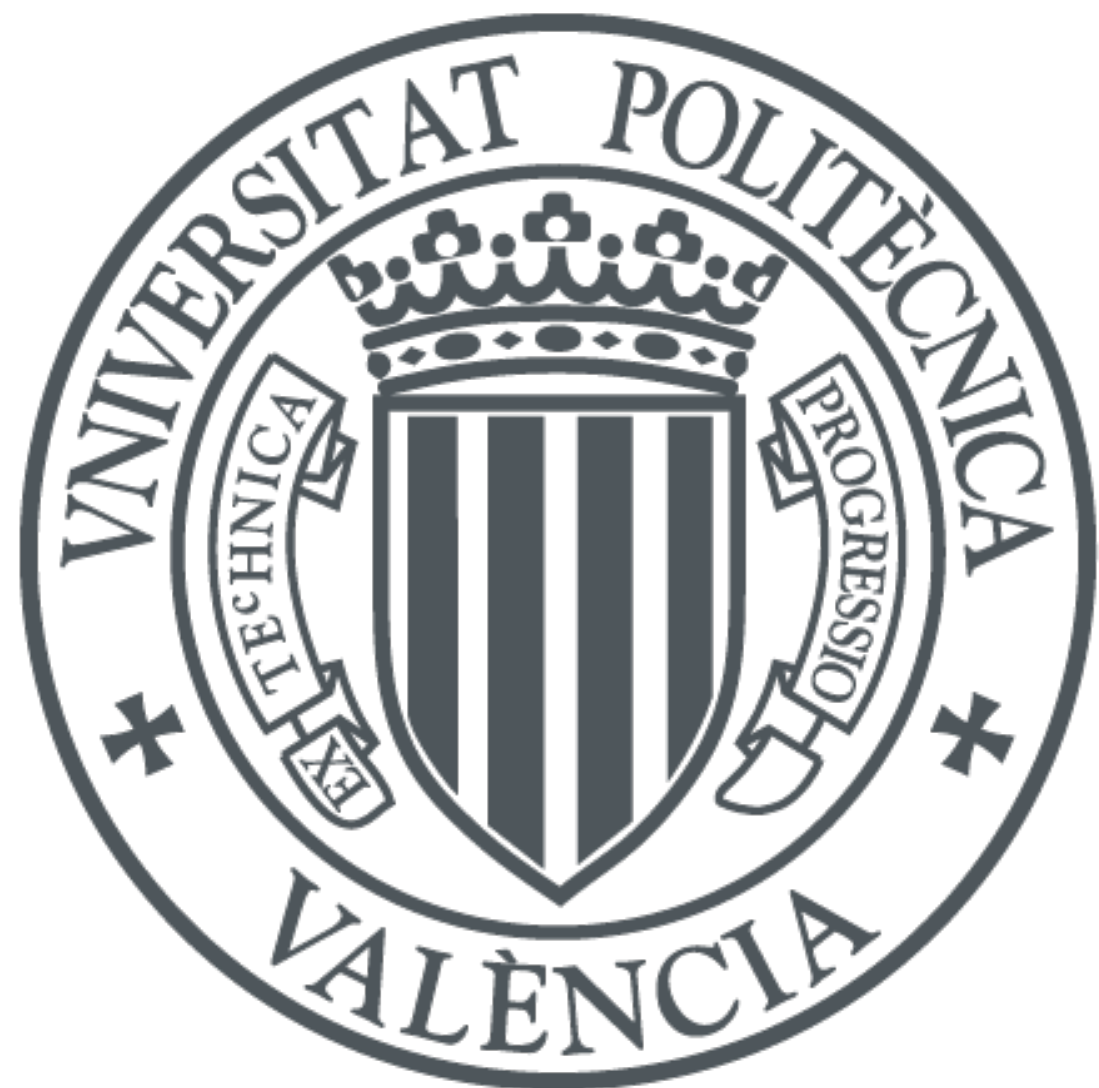

The final publication is available at

https://doi.org/10.1061/9780784482889.023

Copyright American Society of Civil Engineers

Additional Information

This material may be downloaded for personal use only. Any other use requires prior permission of the American Society of Civil Engineers. This material may be found at https://doi.org/10.1061/9780784482889.023 


\title{
Drivers of Innovation using BIM in Architecture, Engineering and Construction Firms
}

\author{
Francisco VILLENA ${ }^{1}$; Tatiana GARCÍA-SEGURA ${ }^{2}$; and Eugenio PELLICER ${ }^{3}$ \\ ${ }^{1}$ Assistant Professor, Construction Engineering Department, Universidad de Sevilla, \\ C/ Virgen de África, 7, 41011 Sevilla, (+34) 954552815; FAX (34) 954282777. \\ Email: fvillena@us.es \\ ${ }^{2}$ Assistant Professor, Construction Engineering Department, Universitat Politècnica \\ de València, Camino de Vera, s/n, 46022 Valencia, Spain (34) 963879562; FAX \\ (34) 963877569. Email: tagarse@upv.es \\ ${ }^{3}$ Professor, School of Civil Engineering, Universitat Politècnica de València, Camino \\ de Vera, s/n, 46022 Valencia, Spain (34) 963879562; FAX (34) 963877569. Email: \\ pellicer@upv.es
}

\begin{abstract}
Architecture, engineering and construction (AEC) firms need to innovate in order to increase their business' competitiveness. Many companies around the world are considering the possibility of implementing Building Information Modelling (BIM) in their projects without knowing its actual benefits for the business. The current literature recognizes certain barriers to BIM implementation; therefore, considering these barriers, this work proposes a holistic model that allows managers to explain how BIM can play an important role for the success of the AEC companies. The pillars of the model are a collaborative culture and training of employees in order to break down technological barriers. This way, BIM can help AEC companies to innovate. This proposal takes into consideration the three phases of the infrastructure life-cycle. In the design phase, the model considers 3D shape, scheduling (4D), costs (5D) and sustainability (6D). In the construction phase, the model focuses on supply chain and quality management. During the operation phase, the model is related to the virtual management of maintenance activities. Drivers of innovation should consider several facets: marketing, technology, organization, processes and products. This model aims to enlighten the positive effects of a good strategic management using BIM on innovation activities in each of the phases of the infrastructure life-cycle.
\end{abstract}




\section{INTRODUCTION}

BIM (Building Information Modeling) has been a factor of cultural change by renewing operational management in the construction industry (Azhar 2011). The BIM technology and methodology is applicable to all phases of the infrastructure lifecycle and to all the stakeholders involved at one time or another, from the owner to the asset manager, including the design team, the construction-site team, the equipment manufacturer, the specialist, the public agency, the investor, the insurer, the end user, etc.

There is a growing literature on the adoption and implementation of BIM and the established literature on innovation by developing the notion of contexts integrated in the innovation process. The performance of an organization tends to be associated with its capacity for innovation, being it a challenge in the construction industry, partly due to the complex nature of this industry (Yusof et al. 2017).

The study of innovation in the construction industry is relevant if the relationships between the drivers of innovation with other facets of business strategy and environment are explored (Blayse and Manley 2004). In construction, there are multiple stakeholders and, therefore, innovation is developed at the project level, being motivated by a large number of factors (Ozorhon and Oral 2016). Therefore, understanding how innovation can be promoted in the construction industry and the types of innovation that are encouraged using BIM technology throughout the infrastructure life-cycle is vital for the construction industry.

The arrival of BIM to the construction industry has allowed the encouragement of innovation within a sector anchored in the past for many years. Consequently, the BIM methodology is assuming a technological specialization for the production and management chain of the building and infrastructure (Elmualim and Gilder 2014). This tool allows to build in a more efficient way, reducing costs while allowing designers, builders and other agents involved, to work collaboratively (Poirier et al. 2016). The aim of this study is to explain how the use of BIM in construction projects can generate innovation during the life of a project. For this, through a holistic theoretical model, the types of innovation that can be generated during the different phases of the infrastructure life-cycle are identified when developed through BIM.

The service life of a construction project is composed of design, preconstruction, construction and post-construction (Azhar et al. 2015). Other authors referring to the useful life of an infrastructure divide their useful life into feasibility, design, execution, operation and dismantling (Alshubbak et al. 2015). The operational phase begins from the moment in which the infrastructure is in use, covering about $85 \%$ of the cycle (Volk et al. 2014).

\section{BUILDING INFORMATION MODELING: BIM}

BIM is a set of digital tools (Latiffi et al. 2013) that allows the introduction of work methodologies that are revolutionizing the way in which projects are designed, analyzed, built and managed (Hardin 2009). Over the last decades, numerous

contributions have been conducted in BIM and its characteristics (Aibinu et al. 2014). BIM can be defined as a work methodology that integrates and involves digital 
technologies based on two pillars: communication and collaboration (Azhar et al. 2015; Latiffi et al. 2013). Harness (2008) defines BIM as a digital representation of the physical and functional characteristics of the project while being also a technology used to create the model. For Autodesk (2012), BIM can be defined as an integrated process that improves the understanding of the project and obtains predictable results. This visibility allows all project team members to stay coordinated, while improving accuracy, reducing waste and making informed decisions at the beginning of the process; this helps to ensure the success of the project. Tekla (2013) defines BIM as a process of modeling and communicating the structure of a building in detail to benefit the entire life cycle of the building. Miettinen and Paavola (2014) define BIM as the digital representation of parametric visual objects (3D) that include geometric information, as well as functional, semantic and topological information related to the different processes and applications involved during the life cycle of buildings. Succar and Kassem (2015) explain that BIM is a current expression of digital innovation in the construction industry. From the analysis of the different contributions on BIM, in this work BIM is considered as an integrated and participatory process that improves the digital representation of projects, optimizing the analysis of the construction (time, cost and procedures), to guarantee success in the execution of the project.

BIM requires collaboration between different stakeholders during the different phases of the infrastructure life-cycle (Poirier et al., 2016). This collaboration seeks to insert, extract, update or modify information in the model itself, supporting and reflecting the roles among stakeholders (Enegbuma et al. 2014). On the other hand, the literature recognizes that BIM implementation in construction projects is satisfactory for cost reduction throughout the entire infrastructure life-cycle (Talebi 2014; Lu and Lee 2017). Currently the efforts of investments in BIM technology are focused on three phases: design, construction, and operation/maintenance. As it is known, in the operation and maintenance phase, BIM is presented as a necessity for efficient management during the operational phase (Kelly et al. 2013). The use of BIM applied to Facility Management (FM), aims to ensure the optimal functionality of all construction facilities involving: people, places, processes and technologies (Roper and Payant 2014). Therefore, it can be said that the innovation model presented in this work is also valid for all companies in the construction industry, including architectural and engineering firms, and concessionaires.

\section{ISO 19650 regulation}

In the current times of Big Data, the economic growth of technology-based companies is determined by knowledge management, learning capacity and R\&D. In particular, knowledge in a company is key for improving its management and competitiveness (Du Plessis 2007). Currently, many companies in the construction sector are making a great effort to implement the BIM methodology (Hong et al. 2019). Such implementation requires collaborative work between the different agents of the construction process of any project (Azhar et al. 2015; Latiffi et al. 2013). In fact, knowledge management in BIM projects is related to the creation, storage, transfer and application of knowledge within a virtual 3D model of the project (Aibinu et al. 2014). The size of the project also conditions the optimal management 
approach. But, is there any regulation regarding the correct production and management of the model information using the BIM methodology?. The ISO 19650 standard establishes the recommendations for the correct production, management, and sharing of all the information that is produced during the entire infrastructure lifecycle. The proper management of BIM information guarantees compliance with the information requirements of the contractor or client. In addition, the ISO19650 standard is located within a broader standardization framework, such as ISO 55000 for the management of built assets or ISO 21500 for project management, all under the global quality management that ensures the ISO 9001 standard.

As a result, for the proper application of the ISO19650 standard in the tasks of project delivery or asset management, a workflow based on BIM is foreseeable, although the quality of the project is revealed by the designer's experience with BIM, its expertise and its good judgment following national or transnational protocols. Ultimately, the ISO19650 standard tries to clarify that the application of BIM can generate a beneficial added value on the companies to their clients, their supply chains and the effective reduction of the costs throughout the production and the service life of the asset. In short, it aims to the search for competitiveness, efficiency and sustainability throughout the construction industry.

\section{PROMOTING INNOVATION IN COMPANIES USING BIM}

In an environment as competitive as the current one, the survival of the company depends to a large extent on the way in which it is able to develop innovations and to overcome technological advances day by day (Yepes et al. 2016). Innovation means: to anticipate the needs of the market before competitors, to provide quality, to retain customers, to efficiently manage deadlines and to control costs. Therefore, companies in the construction industry must face new challenges to obtain sustainable competitive advantages over time (Pellicer et al. 2014). Some authors question that the use of BIM in projects does not positively impact innovative capacity because different points of views of BIM are adopted according to the work and perspective of each stakeholder (Selçuk Çldlk et al. 2017). In general, it is assumed that BIM is an innovation in itself and plays a key role in the digital transformation of the construction industry and that the innovations are caused by organizational behavior, being better observed at the project level (Papadonikolaki 2018). The analysis of the innovation process in the construction industry must take into account the characteristics of the sector and its stakeholders. Therefore, innovation is developed at the project level and is driven by a large number of factors (Ozorhon and Oral 2016).

In Figure 1, the model of drivers of innovation is shown using BIM. The pillars of the model are the collaborative culture and the training of employees in order to break down technological barriers. Overcoming the barriers, the model starts with the BIM implementation as technological adoption; an aspect already considered in the scientific literature (Taylor and Todd 1995). The technological decisions adopted at present will be linked to the subsequent learning process, determining the future trajectory of the innovation process (David 1975). One of the problems in the implementation of BIM is overcoming the technological barriers that its adoption implies (Zhou et al. 2019). The BIM implementation requires training of the project 
team and some experience, and making an important initial effort (Khosrowshahi and Arayici 2012). Once the technological barriers have been overcome, the proposed model divides the useful life of a construction project into three phases: (1) design, (2) execution, and (3) operation and maintenance.

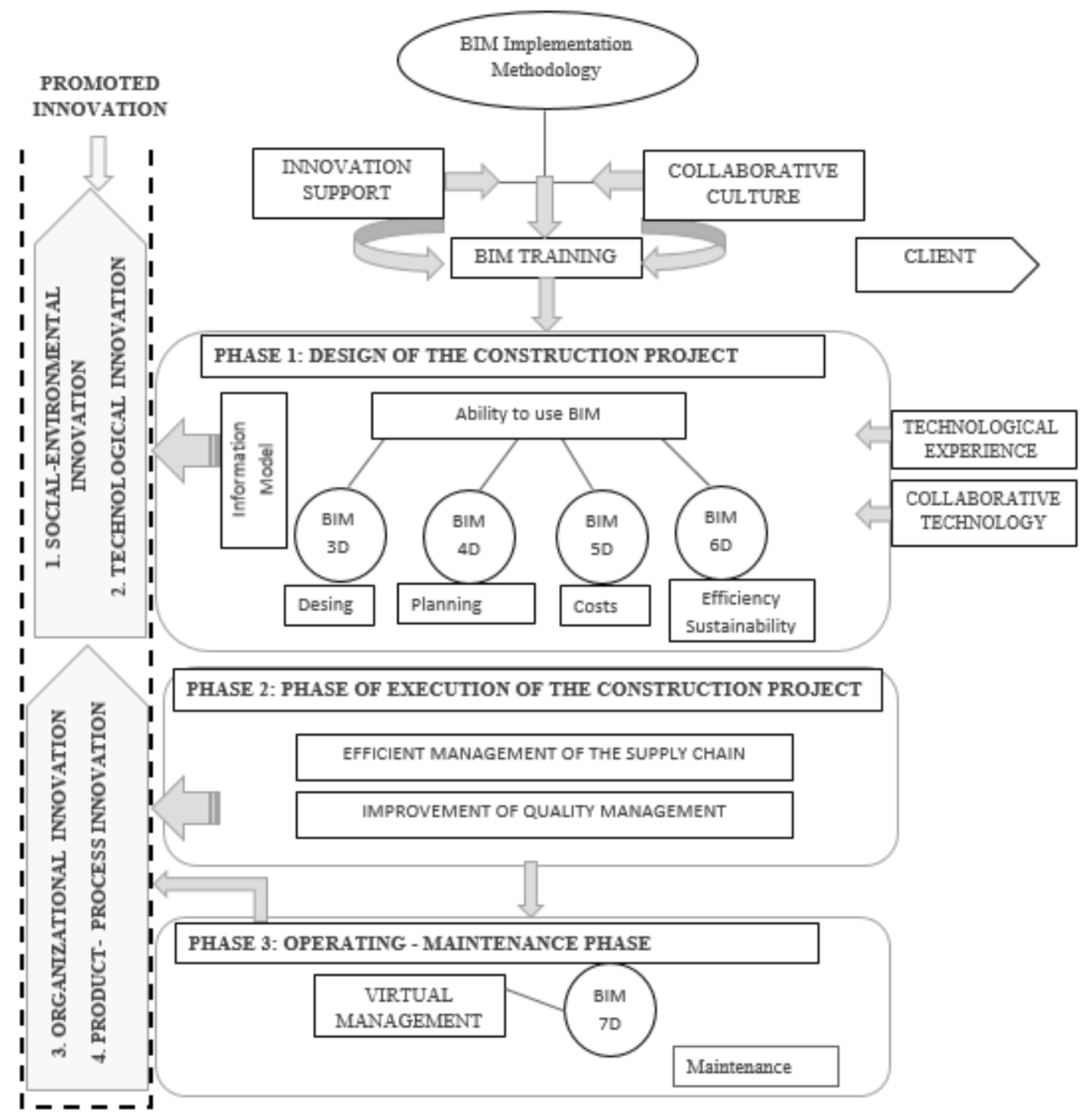

Figure 1. Drivers of innovation in companies using BIM

\section{Phase 1: "Innovation in the design phase"}

Compared to three-dimensional CAD models, BIM models allow the creation of objects that contain parametric, quantitative and qualitative characteristics (Muñoz et al. 2017), such as construction method, material, supplier, brand, model, physical dimensions, and thermal behavior, among others. Similarly, these models allow the generation of different views from the same model, facilitating the revision according to ISO 19650, and allowing cost estimation (BIM 5D), construction planning (BIM 4D) and identification of conflicts or interferences (Azhar 2011). It should be 
clarified that BIM is implemented from several softwares, used in a complementary way. However, it is not limited to these or the three-dimensional model. In fact, BIM goes further, even involving different cross-cutting processes.

BIM 3D corresponds to the creation of the three-dimensional model. BIM 4D is the model with built-in times and scheduled construction tasks (Gascueña et al. 2018), allowing the user to make a visual simulation of the sequence of construction processes in the design phase of the project (Ramos et al. 2016). The fifth dimension (BIM 5D) involves the cost of construction and facilitates the calculation of the number of tasks (Franco et al. 2015). The sixth dimension (BIM 6D) is linked to the environmental sustainability of the project, thus facilitating the process for a certification of the building.

Sustainable development is part of the actions in environmental policies, of a territory or nation. Sustainable development meets the needs of the present, without compromising the ability of future generations, to meet their own needs (Van Hauwermeiren 1998). Sustainable development policies ae closely related to urban development. This is where the term "Green Cities" comes into play, which are conceived as spaces that reduce environmental pollution, provide renewable energy, use resources (water and energy) in the most efficient way, recycle waste and, finally, include green areas within urban planning (Villena and Galiano 2017). Green innovation consists in the search, promotion and development of ecological products, services and processes that incorporate a certain degree of novelty (Chen 2008). For that reason, the integration of environmental sustainability issues into the corporate strategy and the innovation process of companies is becoming a strategic opportunity for them (Porter and Reinhardt 2007).

In the design and construction phases (BIM 3D up to 6D), BIM allows integrating these sustainable issues (materials, energy studies, etc.) of the project in order to improve the well-being of the end user. The term "social innovation" is used to describe the development and implementation of new ideas (products, services and models) to meet social needs (OECD 2008). Based on the above, it can be said that in the design phase, BIM allows social innovations to be carried out. Therefore, a social and environmental innovation can be generated in this first phase related to design.

In this study, the concept of technological innovation is used to describe the process through which technological advances happen. Technological innovation reflects the variations experienced by the volume of available technologies over a period of time. The innovation process encompasses a set of activities that contribute to efficiently improve the use of the building or infrastructure. Kleinschmidt et al. (2007) refers to technological innovation as organizational resources (culture of innovation, commitment of resources, involvement of management) that define the context in which technological innovation activities take place, and more specifically, the attitude towards innovation of the top management of the company.

Therefore, the concept of technological innovation through BIM is associated with an idea of flow, application and diffusion of technologies. Therefore, the implementation of BIM generates technological innovation within the innovation process of the company during the project design phase. 


\section{Phase 2: "Innovation in the construction phase".}

In this phase of the infrastructure life cycle, the verification and control of the 3D model designed for its correct commissioning and execution is carried out. This phase allows the estimation of the virtual model costs (BIM 5D), and the control of the construction planning (BIM 4D), for the delivery of the construction in the terms stablished by contract. In this phase, the identification of conflicts or interferences is necessarily carried out (BIM 4D and BIM 5D). On the other hand, Weerawardena et al. (2006) defends organizational innovation as the application of ideas that are new to the company, whether the novelty materializes in products, processes and management or marketing systems. As it can be deduced, the implementation of BIM $4 \mathrm{D}-5 \mathrm{D}$ is a new way to manage the infrastructure during the construction phase. BIM involves a new philosophy of collaborative work in order to add value from the companies that implement it to their customers, improving their supply chains and effectively reducing costs throughout the production and service life of the active. This phase also aims to minimize errors by contractor; the virtual model allows verifying a comprehensive management of the quality of the project with the correct management of all the information that is produced during the entire infrastructure life-cycle. The right management of BIM information guarantees compliance with the information requirements of the contractor or the owner. Therefore, it can be easily understood how organizational innovation is encouraged at this stage and, at the same time, product innovation (for improving costs and increasing quality and reducing delivery times) and process innovations, since BIM starts up new ways of asset production.

\section{Phase 3: "Innovation in the operation and maintenance phase".}

In the third phase of the model, the construction is being used by the end user, entering the seventh dimension (BIM 7D) corresponding to FM and the activities needed for the operation of the asset (Ramos et al. 2016). BIM technology is able to develop in the same 3D model, all architectural, structural, electrical, hydraulic, etc. components, housed in a virtual repository with all documentation generated from the project in order to be used in maintenance (BIM 7D). This last phase includes maintenance operations activities, in which the largest investment is concentrated. BIM has a new impact on organizational-process-product innovation to update the inventory and suitable operation of the asset in service.

\section{CONCLUSIONS}

The construction industry needs a practical vision of innovation to better understand and know how it can be encouraged in projects. Performing a theoretical analysis of the innovation process should include the characteristics of the sector and the stakeholders. Therefore, innovation is developed at the project level. In this paper it is studied the innovative capacity of the companies by using BIM. To carry out this study at the project level, the types of innovation boosted by phases of the project life cycle (design, construction and operation) have been distinguished. During the design phase, it is possible to promote social - environmental innovation and technological innovation. During the construction phase, it is possible to promote organizational innovation and process-product innovation. Finally, during the operation phase, using BIM for the facility management activities affects the organizational-process-product 
innovation for the update of inventory and proper functioning of the asset in service. In summary, this paper intends to give a holistic vision of encouraging innovation using BIM in the construction industry. Professionals are offered a new vision to establish novel ways of doing things to improve their daily work. This study aims helping project managers propose appropriate strategies to implement innovation using BIM in construction projects.

\section{REFERENCES}

Ahmad Latiffi, Aryani and Mohd, Suzila, Kasim, Narimah and Fathi, Mohamad Syazli. (2013). "Building Information Modeling (BIM) Application in Malaysian Construction Industry". International Journal of Construction Engineering and Management. 2. 6. 10.5923/s.ijcem.201309.01.

Alshubbak, A., Pellicer, E., Catalá, J., and J. M. Teixeira. (2015). "A model for identifying owner's needs in the building life cycle". Journal of Civil Engineering and Management, 21(8), 1046-1060.

Aibinu, A. and Venkatesh, S. (2014). "Status of BIM Adoption and the BIM Experience of Cost Consultants in Australia". Journal of Professional Issues in Engineering Education and Practice. 140. 04013021. 10.1061/(ASCE)EI.1943-5541.0000193.

Autodesk, Inc. (2012). Building information modeling [online], [ 8-06-2012]. Available from Internet: http://usa.autodesk.com

Azhar, S., Khalfan, M and Maqsood, T. (2015). "Building information modelling (BIM): Now and beyond". Construction Economics and Building. 12. 15-28.

Blayse, A. and Manley, K. (2004). Key influences on construction innovation. Construction Innovation,4(3), 143-154

David, P. (1975). Technical choce, innovations and economic growth. UK : Cambridge University Press.

Du Plessis, M. (2007). "The role of knowledge management in innovation". Journal of Knowledge Management,11(4),20-29.

E. Porter, M. and Reinhardt, L.F. (2007). A strategic approach to climate. Harvard Business Review. 85. 22-26+162.

Elmualim, A. and Gilder J. (2014). "BIM: Innovation in design management, influence and challenges of implementation". Architectural Engineering and Design Management. 10. 10.1080/17452007.2013.821399.

Enegbuma, W., Ologbo, A., Aliagha U. and Ali, K. (2014). Preliminary Study Impact of Building Information Modelling Use in Malaysia. Shuichi Fukuda; Alain Bernard; Balan Gurumoorthy; Abdelaziz Bouras. 11th IFIP International Conference on Product Lifecycle Management (PLM), Jul 2014, Yokohama, Japan. Springer, IFIP Advances in Information and Communication Technology, AICT-442,51-62, Product Lifecycle Management for a Global Market.

Franco, J., Mahdi, F., and Abaza, H. (2015). "Using building information modeling (BIM) for estimating and scheduling, adoption barriers". Universal Journal of Management, 376-384.

Harness, S. H. (2008). 2008 documents AIA advance the use of BIM and integrated project delivery [online], [5 Diciembre 2008]. Available from Internet: http://www.aia.org

Hong, Y.,Hammad, A., Sepasgozar, S. and Akbarnezhad, A. (2019). "BIM adoption model for small and medium construction organizations in 
Australia", Engineering, Construction and Architectural Management, 26(2), 154-183. https://doi.org/10.1108/ECAM-04-2017-0064

ISO 19650-1:2018 Organization and digitization of information about buildings and civil engineering works, including building information modelling (BIM) Information management using building information modelling - Part 1: Concepts and principles

ISO 19650-2:2018 Organization and digitization of information about buildings and civil engineering works, including building information modelling (BIM) Information management using building information modelling - Part 2: Delivery phase of the assets

Khosrowshahi, F. and Arayici, Y. (2012). "Roadmap for implementation of BIM in the UK construction industry". Engineering, Construction and Architectural Management. 19. 10.1108/09699981211277531.

Kleinschmidt, E.J., De Brentani, U. and Salomo, S. (2007). "Performance of Global New Product Development Programs: A Resource-based View". The Journal of Product Innovation Management, 24, 419-441.

Lu, Q. and Lee, S. (2017). "Image-Based Technologies for Constructing As-Is Building Information Models for Existing Buildings". Journal of Computing in Civil Engineering. 31. 04017005. 10.1061/(ASCE)CP.1943-5487.0000652.

Miettinen, R. and Paavola, S. (2014). "Beyond the BIM utopia: approaches to the development and implementation of building information modeling", Automation in Construction.43,84-91.

Muñoz, J.S., Alvarado, R.G., Arcas, J.P., and Aravena, G.A. (2017). "The implementation of the Building Information Modeling Methodology (BIM) for buildings established in Chile". Blucher Design Proceedings, 486- 491.

Organization for Economic Cooperation and Development, OECD. (2008). Sustainable manufacturing and eco-innovation: First steps in building a common analytical framework, DSTI/IND, 16/REV 1.

Ozorhon, B. and Oral, K. (2016). "Drivers of Innovation in Construction Projects ". Journal of Construction Engineering and Management. 143. 04016118. 10.1061/(ASCE)CO.1943-7862.0001234.

Papadonikolaki, E. (2018). "Loosely Coupled Systems of Innovation: Aligning BIM Adoption with Implementation in Dutch Construction". Journal of Management in Engineering. 34. 10.1061/(ASCE)ME.1943-5479.0000644.

Poirier, E., Staub-French, S. and Forgues, D. (2015). "Embedded contexts of innovation", Construction Innovation, 15 (1), 42-65.

Poirier, E., Forgues, D. and Staub-French, S. (2016). "Collaboration through innovation: implications for expertise in the AEC sector". Construction Management and Economics. 34. 1-21. 10.1080/01446193.2016.1206660.

Ramos, L. F., Rugel, R. R., and Aguilar, J. M. (2016). Beyond technology: BIM as a new philosophy. Civilizate, 46-49.

Selçuk Çldlk, M and Boyd, David and Thurairajah, N. (2017). "Innovative Capability of Building Information Modeling in Construction Design". Journal of Construction Engineering and Management. 143. 10.1061/(ASCE) CO.19437862.0001337. 
Succar B. and Kassem, M. (2015). Macro-BIM adoption: conceptual structures, Automation in Construction. 57: 64-79.

Tekla Corporation. (2013), Basic concepts [online], [ 16 Enero 2013]. Available from Internet: http://www.tekla.com

Van Hauwermeiren, S. (1998). Manual of Ecological Economics, Ecological Economics Program, Institute of Political Ecology, Chile

Villena Manzanares, F. and Galiano, A (2017). "Sustainable urban development and its implications for enterprises and territories". Journal of Business Studies. Second Era 10.17561/ree.v0i1.3185.

Volk, R., Stengel, J. and Schultmann, F. (2014). "Building Information Modeling (BIM) for existing buildings - Literature review and future needs". Automation in Construction. 38, 109-127. 10.1016/j.autcon.2013.10.023.

Yepes, V. Pellicer, E. Alarcon, L. and Becerra, CL. (2016). "Creative Innovation in Spanish Construction Firms". Journal of Professional Issues in Engineering Education and Practice. 142. 04015006. 10.1061/(ASCE)EI.19435541.0000251.

Yusof, N. Seng Lai, K and Mustafa Kamal, E. (2017). "Characteristics of innovation orientations in construction companies", Journal of Engineering, Design and Technology, 15(4), 436-455. https://doi.org/10.1108/JEDT-06-2016-0037

Zhou, Y, Yang Y, and Yang, J.B. (2019). Barriers to BIM implementation strategies in China. Engineering, Construction and Architectural Management. 26. 10.1108/ECAM-04-2018-0158.

Chen, Y-S. (2008). "The driver of green innovation and green image - Green core competence". Journal of Business Ethics, 81,531-543.

Gascueña, N. V., Fernández, J. P. R., and Sáez Pérez, M.P. (2018). Experiencia docente colaborativa entre universidades. Desarrollo de las dimensiones 4D y 5D a partir de un modelo 3D BIM, 63-79.

Roper, K., and Payant, R. (2014). The facility management handbook. Amacom 